\title{
Multilingual Learner's Thinking Rhetoric: Changes in Language Rhetorical Style
}

\section{Raga Driyan Pratama}

Universitas Negeri Surabaya, Indonesia.E-mail: ragapratama16070835073@mhs.unesa.ac.id

\begin{tabular}{l} 
ARTICLE INFO \\
\hline Keywords: \\
Multilingual learners; \\
Thinking Rhetoric; \\
Thinking Changes \\
How to cite: \\
Pratama, R D., (2018). \\
Multilingual Learner's \\
Thinking Rhetoric; \\
Changes in Language \\
Rhetorical Style, 4(2), 138- \\
148. \\
DOI: \\
http://dx.doi.org/10.31332/ \\
lkw.v4i2.933
\end{tabular}

\begin{abstract}
Language and cognition are interdependent elements which are currently relevant to second language acquisition issues. Learners will simultaneously acquire the thinking rhetoric carried out by a target language once they acquire the language itself. The externalization of the cognitive process can be seen from learner's writing product or speaking performance that have been greatly investigated by numbers of researchers. The proposed problem was what happened to multilingual learner's thinking rhetoric. Did they easily change between one language rhetorical styles to another? Or, their cognitive control mechanism was just intersected? This study aims at reviewing the concept of multilingual learner's thinking rhetoric along with their externalizations. It is expected that this study contributes to unlocking the dilemma of learners' cognitive problems when acquiring multi-language and initiating further research concerning how to handle multilingual learners' language rhetorical styles.
\end{abstract}

\section{Introduction}

When acquiring a language, unconsciously learners also get infused the thinking rhetoric of a target language they want to master. This claim has been confirmed by Pawlak \& Aronin (2014) whose study investigated how the thinking rhetoric was permeated within the language acquisition process. In most results, learners convey a particular rhetoric due to the awareness of the concept of the target language. In this case, the diverse concepts appear since language is a cultural bound which has different aspects and ways of communication either verbally or nonverbally (Srivastava \& Goldberg, 2017; Gunawan, 2012; Brock-Utne, 2005; Jiang, 2000). That is, it is true to constitute that acquiring a language is about the ability to permeate every single aspect influencing of its natural mastery.

However, the focus of related problems to above phenomena should not be addressed only to those being monolingual. Instead, the variety of problems will appear in both bilingual and multilingual learners, of which are more complicated issues dealing with cognition. Bilingual learners are those who acquire two languages which consist of two contrastive thinking rhetoric (Diamond, 2010). Besides, this type of learners also possesses two different mental grammars, further known as an interlanguage (Ellis, 1997), that possibly exist a messed externalization 
due to imbalance language development. For instance, Wade was an American whose first language (L1) is English and moved to Mexico City for college lives, in which her nearby Mexican friends spoke in Spanish. Previously, she knew Spanish as her second language (L2) because she was taught by her grandmother, a Mexican. Even so, she still spoke in English while she was in America. Once in Mexico, since the language milieu exposed to her was Spanish, she became fluent in Spanish after reaching six months, while her L1 started to be fossilized. Surprisingly, when going back to Washington, DC, for a couple of days, she wanted to ask for using a washing machine, "Dad, can I use the lavadora?" Indeed, her Dad did not know what lavadora was and were sure that she never happened to mix English and Spanish once talking. This short vignette shows how a bilingual learner comes to a confusedness of acceptably externalizing an interlanguage due to imbalance language development.

To cope with Wade's case, Kroll (2015) argues that the phenomenon could occur since two mental grammars may converge or, often, compete for one another. This is due to the changes in cognition and brain caused by the exposition to different language experiences (Kroll, 2015; Kroll \& Dussias, 2017). For example, in Wade's problem, she must be having two different language experiences that affect the improvement of her L1 or L2. When she was in America and living a life using L1, she must get more exposures to English experience than of Spanish, her L2. According to Kroll (2015), this condition gives different benefits to a language acquisition development as the language milieu more activates a language processing which is relevant to the milieu. That is when Wade lived in Mexico and fluently spoke in Spanish for six months long, she tends to still use some Spanish vocabularies or rhetoric on the first day of coming back to Washington, DC.

Wade's case is unluckily only about sentence construction which has a little connection to the unequivocal difference of thinking rhetoric. Filipović (2016) tells another vignette about how bilingual learners used the L1 thinking rhetoric to produce L2 aural discourse. Her study reveals that learners whose native is Spanish still use Spanish rhetoric in speaking instead of using English rhetoric as the second language when producing English speech. As a theoretical contribution, she pointed that using L1 patterns or rhetoric will help L2 learners voice the ideas in L2 speaking easily. By addressing the results, Filipović (2016) in the same time claims that there are two different thinking rhetoric brought by two languages. That is, being bilinguals raise a consequence in mind and brain changes proven by the externalization they make (Kroll, 2015).

Now, can you guess what happened to Wade and 28 Filipović's students if they acquire multi-language? What happened to their architecture of cognition? Does their thinking rhetoric always change depending on the language used, or, simply interexchange? This study aims at profoundly discussing multilingual learners' thinking rhetoric and its effect on their language use or rhetorical style. This study begins with theoretical explanations regarding language acquisition and followed by the related theories concerning on language and cognition, fundamental concepts how multilingual learners differ from the bilingual ones, and their rhetorical language changes when producing externalizations supported with some case studies. 


\section{Language Acquisition}

Many of novice academicians might be still wondered what second language acquisition is. Ellis (1997:3) conceptualizes the second language as "any language that is learned after the mother tongue." The definition does not merely refer to a particular language, rather, it comprises the third, the fourth, or the fifth languages afterward (Ellis, 1977). Second language, or familiarly known as L2, always has a great deal with acquisition, meaning that, both are inseparable. The word acquisition itself bears different perspectives regarding its meaning how it differs from learning. This study describes acquisition as the way how a person masters a language regardless the debates on its aspects about formality, effectiveness, and deliberativeness. This is because different people might experience acquisition in a different setting, including dissimilar applications of the involvement in the aspects above. However, unconsciousness in mastering a certain language might still become a considerable aspect in related to acquisition's characteristic. That is this study in short defines L2 acquisition as a way how a person masters languages other than his mother tongue (L1) and can use them like naturally (Ellis, 1997).

When such definition applied, L2 acquisition would be very much easier to understand how it plays with both institutional and social roles. Common paradigms which put acquisition and learning separately are the major causes why several academicians reject how come L2 acquisition can cover the two roles simultaneously. For instance, the common paradigms view L2 acquisition is more into an informal setting (e.g., happened outside of teaching and learning process in the classroom) while learning more formal (e.g., inside classroom activities). Meaning that, with such a paradigm, a learner language might be impossible experiencing acquisition within classroom activities. This study then says the acquisition might happen everywhere since it is unconscious no matter whether it is deliberative and formal or not. Therefore, Ellis (1997) conveys that L2 acquisition can happen in institutional or social settings since language use for communication for different communities has been beyond one's native language.

The current issue of L2 acquisition is nowadays about the core of language and cognition. L2 acquisition is not merely about acquiring a language. Rather, it includes the shaping of the cognition of one's mind due to different language carries dissimilar cognitive rhetorical style (Pawlak \& Aronin, 2014; Lewis, 2006; Kroll, 2015; Spack, 1997). Some previous studies have worked on such topics with different scopes to engage. For example, Stam (2010) conducted a study focusing on the investigation of linguistics relativity in L2 acquisition. He argued that a learner of both Spanish and English language showed changes in thinking-for-speaking patterns. Moreover, Langer (2001) also constituted that once language being acquired by a learner, the learner's whole cognition aspects of the acquired language will grow simultaneously in a parallel mode (see section 5 for the explanations). To study on the cognitive development of a certain language, section 3 firstly introduces a widerange of discussion related to the operational process of the acquired languages in the brain.

\section{Language and Cognition}

Before leading to the heart of the issue, it is important to understand language 
in nature at a glance. Smith (2008) describes that language becomes a communication medium that is agreed and understood between two persons, or among people in bridging understanding. However, this concept should not be mistaken by generalizing that language is only about communication. Rather, it carries cognitive mental acquisition in which this study calls it a language rhetorical style. The different patterns of cognition may be interfered by cultures. Thus, the theory of socio-cultural thinking rhetoric becomes well-known (Kaplan, 1966). Unfortunately, nowadays, it seems difficult to see one's cultural backgrounds and determine to which cultural group one should belong because of the fluidity of cultures. This is because cultures are less contributive in judging people's cognition (Rosaldo, 1993; Spack, 1997). Moreover, "language and cultures are tied to racism and prejudice" (Smith, 2008:4). Further, it constitutes that rhetorical construction dealing with cognition is more influenced by the language used and its rhetorical style application (Rosaldo, 1993; Spack, 1997).

Now, how does the cognition work when dealing with language? First of all, it is necessary to see this case into more psychologically and scientifically. To cope with the issue, there are four different cognitive functions namely attention, inhibition, working memory and set shifting (Elmer, et al., 2014). These four executive functions lay on one part from a set of neural devices namely inferior frontal cortex (Elmer, et al., 2014). Abutalebi\& Green (2007) explains that, in the cortex, the four cognitive functions work at controlling multiple language systems along with each its different rhetorical style. Simply, the executive control seems like raising an understanding that the brain has already put languages in boxes where each of them carries different characteristics including the language rhetorical style.

Also, the executive control done by cognitive functions aims at dealing with the various mechanism. This process is further familiar with a term cognitive control mechanism (Elmer, et al., 2014). This control mechanism is prerequisite for "solving interactions between L1 and L2 during language production, switching between languages, producing words in the weaker-spoken language, accomplishing translation and interpreting tasks, and inhibiting non-target language during speech production" (Elmer, et al., 2014:180). To bring the mental mechanism into more practical performance, there is a study investigating how the human brain works in dealing with multiple languages. Elmer, et al. (2014) finds that there is a reduced grey matter (GM) volume, a part of fMRI result that indicates the cognitive process, in an fMRI result of a professional simultaneous adult interpreter. This shows a hard process of the brain in switching languages from one to another. It is because switching language is also switching the boxes that consist of multi aspects covering a language rhetorical style. Thus, cognitive control mechanism becomes an important role in dealing with language and its cognitive aspects.

Further, the cognitive control mechanism will work better during the times of usage. In other words, the more the cognitive control mechanism gets to expose, the easier switching between languages. This development process can lead to a condition where a brain performs balanced language experience and reach so-called a brain maturation. As an implication to those possessing multiple languages, it is good to see changes of language experience, exposures to the cognitive control mechanism, and other activities involved in language and cognition because these 
activities will produce cognitive advantages (Bialystok, 2017; Bialystok \& Poarch, 2014; Li, Legault, \& Litcofsky, 2014).

\section{Bilingual and Multilingual Learners}

Currently, so many people in the world have become bilingual and multilingual speakers. Just a few of them are monolingual (Smith, 2008). Bilingual speakers often show diverse language proficiency between one another including but not limited to those who still learn, called bilingual learners. One aspect that can portray out the level of proficiency is the mastery of vocabulary (Stam, 2010). Bialystok (2017) argues that bilingual learners have a smaller vocabulary size in each language compared to that of monolinguals. However, these typical learners have greater metalinguistic awareness, a capability to understand linguistic structure (Bialystok, 2017). On the contrary, there is a group of learners who learn or acquire more than two languages and are active of using the languages called as multilingual learners (Diamond, 2010). They might be able to perform various practices of codeswitching. Moreover, their brain could be performing harder cognitive control mechanism due to multiple languages they master. It has been validated that multilingual's fMRI result shows an increased GM, of which is claiming the presence of more effective brain activation (Elmer, et al., 2014; Li, Legault, \& Licofsky, 2014).

Also, bilingual and multilingual learners indeed perform cognitive control mechanism carried out by the cognitive functions differently. Bilingual learners who operate two languages in the brain are less burdening to the cognitive functions than those multilingual. In that case, bilingual learners' cognitive control mechanism only works, for instance, on solving an interaction between the mother tongue and one other language as L2 during the production of speech. For example, a person whose L1 is English and the L2 is Mandarin; his cognitive control mechanism only works on switching the English-to-Mandarin linguistic structure, or vice versa. Now, imagine that a person's L2 is more than one language, let's say Mandarin, Indonesian, and Spanish, which are learned and acquired subsequently one after another. Such multilingual learners indeed face harder cognitive control mechanism to switch from English to Spanish because he must experience three times language switching, namely English-to-Mandarin, Mandarin-to-Indonesian, then Indonesian-to-Spanish. Such working brain performing complicated mechanism is indeed harder than those bilinguals. Therefore, it is very challenging to see how multilingual learners' thinking rhetoric works revealed by the changes of the externalizations they make.

\section{Speciality of Being Multilingual Learners}

Generally, there are two aspects to look at the benefits of being multilingual namely personal and professional points (Kroll \&Dussias, 2017). First, being multilingual efficiently activates the brain performance. Diamond (2010) explains that multilingual learners perform better in dealing with various game problems and instructions than those monolinguals or bilinguals. Moreover, being multilingual put learners under protection from having Alzheimer's dementia symptoms when reaching overages (Diamond, 2010) and from cognitive decline (Kroll \& Dussias, 2017; Bialystok \& Poarch, 2014). In addition to cognitive skills, multilingual learners get higher literacy and academic achievements when have been exposed since early childhood education (Bialystok, 2017; Kroll \& Dussias, 2017). Thus, by a personal 
aspect, multilingual learners possess better cognitive advantages (see Bialystok \& Poarch, 2014).

Regarding the cognitive skills, multilingual learners experience numbers of language rhetorical style since Lewis (2006) claims that each language carries on different rhetoric. Lewis (2006) portrays 84 languages with each language rhetorical style for communication in which each language is indeed different. For example, English carries straightforwardness while Indonesian adapts unclear delivery. Another example is from interpreters used in Elmer, et al.'s (2014) study who acquire English, French and Germany trying hard in switching English to French, French to Germany, English to Germany, or vice versa. The speaking rhetoric they deal with switching language to another is also changing. This is due to the different concept of communication pattern when dealing with English, compared to French and Germany. Also, Pratama \& Lestari (2015) also proves that five out of six Indonesian students' L2 writing do not reflect the Western thinking rhetoric. Therefore, it has been justified that learners with Multilanguage mastery are assumed of having multiple rhetoric styles.

Second, being multilingual learners invests pockets of promised future works (Ellis, 1997; Kroll \& Dussias, 2017). Referring to language and its communication purpose, having multiple languages ease the ways of communication in multilingual forums. Moreover, in this $21^{\text {st }}$ century, learners are demanded to acquire several languages used for international communication. This prospective multilingual will also add to the charts of social interactions and opportunities, intercultural understanding, and economic progress (Kroll \& Dussias, 2017). Those capitals are indeed helpful in accelerating a better professional wealth.

When applying one of language, multilingual learners with balanced language experience and development will have no intersection in producing spoken or written externalization. This is because of the activation and habituation of four cognitive functions. When there exist imbalanced ones such as caused by the influence of language milieu, just like in Wade's case, the presence of utterances, words, or other forms of externalization may intersect or interexchange between languages. Likewise, when the production is inter-exchanged, the language rhetorical style will also be mixed and unclear. Therefore, "multilingual learners may not be able to demonstrate all they know in a single mode" (Molle, Sato, Boals, \& Hedgspeth, 2015:7), rather, the externalizations must be intersected. To see the dominance, however, it cannot be retracted by judging learners' first language, or background cultures. Rather, it must be seen to what language the learners tend to master, probably interfered by external factors such as the condition of language milieu.

\section{Multilingual Learners' Thinking Rhetoric}

Various thinking rhetoric have been the most frequently discussed issue among linguists. It also has prompted different perspectives about judging whether certain groups of people who have similar language and culture perceive particular thinking rhetoric. That is, the dissemination of thinking rhetoric based on culture was born (Kaplan, 1966; Jiang, 2000). Regarding today's trend, some scholars often interconnect that issue with higher-order thinking, or critical thinking skills (Pratama \& Lestari, 2015; Pratama, 2018; Rashid \&Hashim, 2008). Most of the studies tried to 
point out how non-native English speakers (NNES) cannot possess English thinking rhetoric for producing good L2 writing (Leonard, 2014; Pratama\& Lestari, 2015). Another study questioned why L2 learners could not produce a straight forward argument as what English natives did (Pratama, 2018). Unfortunately, a few studies consider the influence of mother tongue's rhetorical style which is a relevant aspect for those perceiving multi-languages.

Since each language carries different language rhetorical style, multilingual learners must have various modes in making use of language to communicate (Molle, Sato, Boals, \& Hedgspeth, 2015). Meaning that multilingual learners reflect various communication patterns. Regarding this issue, Lewis (2006) portrayed numerous communication patterns revealed in several communities who use different languages. For example, Indonesian people who speak Indonesian carry the unclear argument. Lewis (2006) showed that Indonesian's communication pattern does not have a climax as a conclusion, rather, they always go around the buss. On the contrary, British people who speak English always have a climax as a link back to what has been asserted (Lewis, 2006). By only referring to those two communication patters, we could realize how every language affects the cognitive of the speakers so that they have different language rhetorical style.

Now, what happened to multilingual learner's thinking rhetoric? Multilingual learners indicate some identities of the language rhetorical style they use (Pratama, 2018). For instance, if they use Indonesian rhetorical style, their circular thinking rhetoric must be reflected in their communication products regardless in oral or written form. So, if their externalizations show half of Indonesian and English rhetorical style, their cognitive control mechanism might have difficulty in totally switching between the two languages. Or, another possibility is that they are still in a negotiation stage between the two languages. When a negotiation process occurred in their cognitive control mechanism, language domination might happen (Leonard, 2014). In this case, certain language rhetorical style might be upper hand than the others. Such phenomena produce externalizations which show imbalanced language rhetorical style. Now, please take a look at the following two paragraphs.

\section{Paragraph 1: Indonesian Rhetorical Style Domination}

Writing an essay is very common in academic life, particularly in colleges. In this level, students are demanded to write an academic writing for writing an essay is the student's duty as an academician. Writing is the most important things a student does at a university. Writing is one of many ways of being assessed. Because it is important, every student is demanded to master academic writing skill (Bowker, 2007:5). At university students are expected to write academically. How the academicians construct their brilliant ideas systematically into writing as well as the choice of appropriate language and words to be understood by, of course, the assessor, lecture, who expects the best from his students, and further by readers. Writing in English requires more skill such as to choose the appropriate words and grammar in line with English structure regulation.

Moreover, it is not enough for the students to have only critical and analytical thinking, the ideas, or to master the writing regulation as well as to set a critical argument but also to have a good standard of grammar. However, the fact is that 
some students very struggle to write academic writing. Brown (2000:341) discussed several characteristics of written languages; one of those is that to write a language is very complicated. "Writer must learn how to remove redundancy, how to combine sentence, how to make references to other elements in the text, how to create syntactic and lexical variety, and much more" (Brown, 2000:342). Hence, writing academically is perceived highly complicated (Jones, Turner \& Street, 1999: vi)

Source: Pratama (2018:361)

Paragraph 2: English Rhetorical Style Domination

In response to pronunciation difficulties, some work has been conducted especially in countries learning English as a foreign language (EFL). For instance, studies conducted to investigate problems with English pronunciation among Thai students and identify key reasons for the problems(Wei \& Zhou, 2002; Khamkhien, 2010). The key reasons of the pronunciation problems are such as words directly borrowed from English into the Thai language are pronounced in Thai ways, the Romanization of the Thai language influencesEnglish pronunciation, and Thai intonations are applied into English pronunciations. They found that there are English consonants and vowels which appear to be problems for them; e.g., words with transcriptions ended with a consonant; consonant clusters; words with /a/, usually pronounced as /e/; words with $/ \mathrm{r} /$, usually pronounced as $/ 1 /$; words with /v/, usually pronounced as /f/; and words with /z/, usually pronounced as /s/ or voiceless, intonation and stress problems. This is to say that the native language is the most influential factor.

Source: Pratama (2018:361)

Both paragraphs were written by Indonesian EFL writers who speak Indonesian and English as their L2. The first paragraph was written by a writer whose mother tongue was Javanese while the second one was composed by a writer whose L1 was Madurese. As for your information, Javanese and Madurese are two local languages with a different hardness of language; Javanese is softer during its use while Madurese is the opposite. By looking at two paragraphs given by Pratama (2018), there was identity domination. Identity here means the indications of certain language rhetorical style. In short, paragraph one shows that the writer tends to dominate Indonesian rhetorical style instead of English to compose L2 writing (Pratama, 2018).

Meanwhile, the second paragraph portrays English domination (Pratama, 2018). If we can look at the trend above, there were no L2 writers with multilingual capability producing compositions with the appropriation of English rhetorical style. The rationale is coming back to the impossibility of the totally switching capacity to the English style. The incapability to totally switch the rhetoric between one 
language to others is because the persons have not successfully acquired the whole rhetoric brought by the targeted language, i.e., English for the above case.

According to Pratama (2018), there are various factors influencing the presence of identity domination, or also known as Leonard's (2014) language domination. First, multilingual learners are hardly being put in a situation where L2 milieu dominates their surroundings. When learners are most frequently closed to their L1 milieu, their mother tongue will dominate the production of language rhetorical style. In other words, the learners are less successful in appropriating English language rhetorical style. However, when the learners are fairly exposed to both L1 and L2 milieus, they might be more accustomed to the languages they learn and acquire, including the successful shaping of the thinking rhetoric laid on the brain. Second, the learners have been habituated to the L1 rhetorical style since born so that the L1 style seems firmly pinned. If it is so, the learners are caged from totally acquiring new language rhetorical style. Further, multilingual learners' cognitive function no longer develops well which affect the obstruction of learners' acquisition of L2 rhetorical style.

\section{Conclusion}

Being multilingual learners are indeed beneficial eventhough some problems appeared hampering the tone of the successful acquisition. This is because these typical learners experience different language exposure that might make one language overlap the others. Moreover, the cognitive process happened in their brain might be harder since too many languages switching they have to encounter. Such a situation may imply the production of communication pattern. They will exhibit intersected language rhetorical styles manifested from their L1 and L2. If the condition of the language milieu is balanced, they probably perform the rhetoric well. On the contrary, they consequently show imbalanced rhetoric that leads to the idea of identity or language rhetorical style domination. This type of domination is a product of negotiation between two or more languages during the production of either oral or written externalization, i.e., oral communication or written discourse. Their externalizations will reflect their thinking rhetoric as a result of acquiring multi-languages. Such a typical situation is not persistent and absolute. The multiple language rhetorical styles portrayed will always change depending on how significant the factors influence the ongoing process of acquisition of the languages. Therefore, this study concludes that multilingual learners' thinking rhetoric will always remain experiencing negotiation until they successfully appropriate the language rhetorical styles.

\section{References}

Bialystok, E. (2017). Second-Language Acquisition and Bilingualism at an Early Age and the Impact on Early Cognitive Development. Encyclopedia on Early Childhood Development, 1-4.

Bialystok, E., \& Poarch, G. (2014). Language Experience Changes Language and Cognitive Ability. National Institutes of Health Public Access, 1-13.

Brock-Utne, B. (2005). The Interrelationship between Language and Culture. 


\section{Evaluation of Education, 1-13.}

Diamond, J. (2010). The Benefits of Multilingualism. Science, 330-333.

Ellis, R. (1997). Second Language Acquisition. NY: Oxford University Press.

Elmer, S., Hanggi, J., \& Jancke, L. (2014). Processing Demands upon Cognitive, Linguistic, and Articulatory Functions Promote Grey Matter Plasticity in the Adult Multilingual Brain: Insights from Simultaneous Interpreters. Cortex, 179189.

Filipović, L. (2016). Speaking in a Second Language but Thinking in the First Language: Language-specific Effects on Memory for Causation Events in English and Spanish. International Journal of Bilingualism, 1-19.

Gunawan, F. (2012). Cyberspace dan Bahasa Alay. Kandai: Jurnal Bahasa dan Sastra, 8(2), 137-147.

Jiang, W. (2000). The Relationship between Culture and Language. ELT Journal, 54(4), 328-334.

Kaplan, R., B. (1966). Cultural Thought Patterns in Inter-Cultural Education.

Kroll, J.F. (2015). On the Consequences of Bilingualism: We Need Language and the Brain to Understand Cognition. Bilingualism: Language and Cognition, 18(1), 3234.

Kroll, J.F., \& Dussias, P.E. (2017). The Benefits of Multilingualism to the Personal and Professional Development of Residents of the US. Foreign Language Annals, 50(2), 248-259.

Langer, J. (2001). The Mosaic Evolution of Cognitive and Linguistic Ontogeny. In Bowerman, M., \& Levinson, S., C. (ed.), Language Acquisition and Conceptual Development (pp. 19-38). UK: Cambridge University Press.

Leonard, R., L. (2014). Multilingual Writing as Rhetorical Attunement. College English, 76(3), 227-247.

Lewis, R.D. (2006). When Cultures Collide: Loading Across Cultures. Boston: Nicholas Brealey International.

Li, P., Legault, J., \& Litcofsky, K.A. (2014). Neuroplasticity as a Function of Second Language Learning: Anatomical Changes in the Human Brain. Cortex, 1-24.

Molle, D., Sato, E., Boals, T., \& Hedgspeth, C., A. (2015). Multilingual Learners and Academic Literacies: Sociocultural Contexts of Literacy Development in Adolescents. New York: Routledge.

Pawlak, M., \& Aronin, L. (2014). Essential Topics in Applied Linguistics and Multilingualism: Studies in Honor of David Singleton. Switzerland: Springer International Publishing.

Pratama, R., D. (2018). Indonesian EFL Teachers' Identities in Written Discourse: English or Oriental Domination? In Madya, S., Hamied, F., A., Renandya, W., A., Coombe, C., \&Basthomi, Y. (eds.), ELT in Asia in the Digital Era: Global 
Citizenship and Identity (p. 361). London: Routledge.

Pratama, R., D., \& Lestari, L., A. (2015). Analysis of Argument and Argumentation Made by S1 Students of English Department. RETAIN Journal, 3(2).

Rashid, R., A., \&Hashim, R., A. (2008). The Relationship between Critical Thinking and Language Proficiency of Malaysian Undergraduate. Proceedings of the EDU-COM International Conference, retrieved from http://ro.ecu.edu.au/ceducom/36

Rosaldo, R. (1993). Culture and Truth: The Remaking of Social Analysis Second Edition. Boston: Beacon Press.

Smith, S. (2008). Supporting Multilingual Learners in the Early Years: Many LanguagesMany Children. NY: Routledge.

Spack, R. (1997). The Rhetorical Construction of Multilingual Students. TESOL Quarterly, 31(4), 765-774.

Stam, G., A. (2010). Can an L2 Speaker's Patterns of Thinking for Speaking Change? In Han, Z., \& Cadierno, T., Linguistic Relativity in SLA: Thinking for Speaking (pp. 59-83). UK: Multilingual Matters.

Srivastava, S.B., \& Goldberg, A. (2017). Language as a Window into Culture. California Management Review, 1-14. 